ISSN $1515-7326, n^{\circ} 16,1 \mid 2015$, pp. 73 a 97

\title{
Tolerancia, modus vivendi y consenso en el liberalismo rawlsiano
}

\author{
Tolerance, modus vivendi and consensus \\ in rawlsian liberalism
}

Fernando A. Lizárraga*

Recepción y evaluación de propuesta: 20/2/2014

Aceptación: 20/03/2014

Recepción y aceptación final: 22/6/2015

\begin{abstract}
Resumen: En este diálogo con René González de la Vega sostengo que la concepción política rawlsiana no es del todo vulnerable a la Objeción contra el Liberalismo Deontológico, pero sí a las objeciones que ponen en cuestión el hecho de que la estructura básica sea el objeto primario de la justicia. Primero, señalo que una objeción situada desde el sujeto de la tolerancia no resulta del todo eficaz, ya que a Rawls no le importan las virtudes personales, sino por razones de la estabilidad. Segundo, sostengo que Rawls concibe la tolerancia como un elemento de la estabilidad, ya que su meta última es el consenso traslapado. Este consenso - no la tolerancia - es la "promesa normativa" para resolver los conflictos entre valores en una sociedad democrática caracterizada por el pluralismo razonable. Tercero, intento mostrar que los Principios de Justicia no actúan como un Sistema Normativo Justificante, puesto que por su carácter estrictamente político no están concebidos como dispositivos para resolver dilemas morales por fuera
\end{abstract}

* Investigador adjunto del CONICET en el Centro de Estudios Históricos de Estado, Política y Cultura (CEHEPyC), Facultad de Humanidades; y profesor adjunto regular de Teoría Política, Facultad de Derecho y Ciencias Sociales, Universidad Nacional del Comahue, Argentina.

E-Mail:falizarraga@yahoo.com.ar y falizarraga@conicet.gov.ar. 
del dominio de lo político, aunque sí resultan pertinentes para dirimir cuestiones de esencias constitucionales.

Palabras clave: liberalismo deontológico, tolerancia, modus vivendi, consenso traslapado.

\begin{abstract}
In this dialogue with René González de la Vega, I uphold that rawlsian political conception is not completely vulnerable to the Objection against Deontological Liberalism, but it is vulnerable to the objections that question the fact that basic structures are the primary object of justice. Thus, first, I point that an objection from the point of view of the subject of tolerance is not entirely effective because Rawls only takes into account personal virtues for stability reasons. Second, I claim that Rawls conceives of tolerance as an element of stability, as his ultimate goal is the overlapping consensus. This consensus - not tolerance- is the "normative promise" to solve conflicts among values on a democratic society characterized by reasonable pluralism. Third, I try to show that the Principles of Justice do not act as a Justifying Normative System because, due to their strictly political character, they are not conceived of as a device solving moral dilemmas outside the political sphere, although they are relevant for settling constitutional issues.
\end{abstract}

Key word: deontological liberalism, tolerance, modus vivendi, overlapped consensus.

\title{
I. Introducción
}

El artículo de René González de la Vega "Legalismo moral y tolerancia. Crónica de una muerte anunciada", constituye, a la vez, una importante impugnación al rigorismo deontológico de cierto liberalismo, y un llamado a considerar la tolerancia como una virtud de agentes morales dotados de prudencia o sabiduría práctica, antes que como un mero dispositivo de "limpieza sistémica" capaz de eliminar toda duda, todo vértigo, todo dilema moral. En las páginas que siguen intentaré establecer un diálogo -y quizás, por momentos, una discusión- con la propuesta de González de la Vega. En este intercambio espero rescatar a Rawls del ataque de nuestro autor, pero solo para terminar coincidiendo en que las virtudes - y entre ellas la toleranciano pueden ser solo institucionales sino también personales. Diré, entonces, que el liberalismo político de Rawls no es del todo vulnerable 
a las objeciones que González de la Vega lanza contra el liberalismo deontológico, pero sí a las objeciones que ponen en cuestión el hecho de que la estructura básica sea el objeto primario de la justicia. Así las cosas, en primer lugar, señalaré (a) que una objeción situada desde el sujeto de la tolerancia no resulta del todo eficaz, ya que a Rawls no le importan las virtudes personales sino por razones de la estabilidad. En segundo lugar, (b) remarcaré que Rawls concibe la tolerancia como un elemento de la estabilidad, ya que su meta última es el consenso traslapado. Este consenso, ya insinuado en Teoría de la Justicia (2000 [1971]) y desarrollado en Liberalismo Político (1996 [1993]), y no la tolerancia, es la "promesa normativa" para resolver los conflictos entre valores en una sociedad democrática caracterizada por el pluralismo razonable. En tercer término, (c) intentaré mostrar que los Principios de Justicia - y en particular el principio de libertades iguales - no actúan como un Sistema Normativo Justificante (SNJ), puesto que por su carácter estrictamente político no están concebidos como dispositivos para resolver dilemas morales por fuera del dominio de lo político, aunque sí resultan pertinentes para dirimir cuestiones de esencias constitucionales.

La Objeción al Liberalismo Deontológico (OLD) desarrollada por González de la Vega, en definitiva, representa una siempre oportuna señal de alarma sobre cómo una teoría moral puede convertirse en un simple mecanismo de limpieza sistémica, que deja poco lugar para los sujetos e incluso para los elementos trágicos de las decisiones éticas y morales. Así, la OLD pone en entredicho aspectos nodales del deontologismo y nos reclama, si se quiere, una mirada más centrada en los dilemas éticos concretos que en la elaboración de un sistema "legalista" capaz de resolver cada caso por el mero expediente de aplicar una regla ya estatuida, de una vez y para siempre. Elaborada en base a una aguda reconstrucción de los puntos salientes del liberalismo deontológico, la OLD presenta generalizaciones necesarias y estimulantes, pero, como ocurre casi siempre con las generalizaciones, hay algunos autores a los que el sayo les cabe más que a otros. Y, en este caso, sostengo que John Rawls puede salir airoso de varios de los cuestionamientos planteados por González de la Vega. 


\section{1. La tolerancia no es (solo) personal, es política}

La OLD está pensada desde el sujeto de la tolerancia; esto es, la persona que debe decidir si un acto debe ser tolerado o no. Y es precisamente esta perspectiva la que hace que el liberalismo político de Rawls pueda salir ileso (o solo con algunos rasguños), toda vez que la doctrina rawlsiana considera que la tolerancia es fundamentalmente una virtud institucional y no personal. Pero antes de avanzar con nuestros argumentos, haremos algunas consideraciones generales sobre la OLD, tal como la expone González de la Vega.

Desde el vamos, el autor nos advierte que no hará una revisión de las diversas concepciones de la tolerancia, sino que su tema es una cuestión de "coherencia filosófica", que apunta a desnudar la incompatibilidad entre el ideal de la tolerancia y el tipo de razonamiento práctico propio del liberalismo deontológico, del cual Rawls es uno de los principales exponentes. En efecto, Rawls dio enormes pasos hacia la "justificación moral" de los principios básicos de justicia escogidos en una escena contractual puramente hipotética. Desde la tradición del contrato social, Rawls sostiene que la moral exige el cumplimiento del pacto, y que los principios seleccionados en dicha escena contractual actúan como imperativos categóricos. Aquello que hemos denominado Objeción al Liberalismo Deontológico se articula, precisamente, en oposición a este dispositivo de cuño kantiano. Según la OLD, en resumidísimas cuentas, el deontologismo constituye una concepción legalista que termina confirmando, moralizando o derogando normas de diverso tipo, y esto es particularmente cierto cuando se trata de la virtud de la tolerancia, entendida como "la práctica de permitir deliberadamente algo que uno desaprueba o disgusta por razones morales"1.

En efecto, la OLD sostiene que el liberalismo rawlsiano expresa una concepción legalista de la moral, que se traduce en cierta propensión a "convalidar la indiferencia ética y a fomentar la imposición de

1 Las citas textuales que no incluyen referencias remiten al artículo de René González de la Vega. Las demás tendrán la correspondiente referencia. 
la moral". Por eso mismo, formulada desde una posición que podríamos llamar pluralista, la OLD culmina recomendando que habría que "prescindir de la tolerancia para la resolución de ciertos conflictos prácticos". Como veremos, jesto es precisamente lo que hace Rawls!, ya que la tolerancia es fundamentalmente una característica de las instituciones bajo un equilibrio de fuerzas que él denomina modus vivendi, una instancia previa e inferior al deseable consenso traslapado donde ya no se requiere tolerancia. Además, la indiferencia ética y la imposición de la moral son cargos que Rawls rechazaría, porque, en efecto, si bien practica la imparcialidad ética, no le son indiferentes las doctrinas comprehensivas; y porque si la moral equivale a los contenidos y los alcances de los principios de justicia, entonces, dicha moral es aceptada por todos a través del dispositivo hipotético de la Posición Original tras el Velo de la Ignorancia.

Ahora bien, según la OLD, el deontologismo liberal se caracteriza por tres rasgos clave, a saber: lo correcto es definido independientemente de lo bueno; lo correcto tiene prioridad sobre lo bueno, y lo correcto no está dirigido a maximizar lo bueno. Y estas tres características descansan sobre una distinción básica entre moral y ética. La primera corresponde al dominio de lo correcto y de lo razonable; la segunda al dominio de lo bueno y de lo racional. De la distinción entre ética y moral, se sigue, siempre según la OLD, que "para esta clase de filósofos [deontologistas] las cuestiones éticas son personales y particulares, mientras que las cuestiones morales reclaman validez y aceptación universal". Vamos a aceptar esta distinción, porque lo que aquí nos interesa es la separación entre lo particular y lo universal; o lo que en el caso de Rawls podríamos llamar, siguiendo a G. A. Cohen, la diferencia entre lo personal y lo político, entre lo personal y lo institucional ${ }^{2}$.

2 Entre muchos otros, la obra de Rawls tuvo el mérito de despertar a ciertos marxistas de su "sopor socialista dogmático". Tal es el caso del filósofo canadiense G. A. Cohen, quien transitó desde la ortodoxia marxista hacia las preocupaciones normativas, para convertirse finalmente en uno de los más refinados críticos de la obra rawlsiana y en un exponente central del igualitarismo de la suerte. 
Este cisma entre lo personal y lo político, según González de la Vega, se manifiesta en el liberalismo rawlsiano, especialmente cuando esta doctrina busca construir una concepción de justicia sin apelar a ninguna noción particular del bien, esto es: "[1]a imparcialidad juega aquí el papel de un punto arquimedeano mediante el cual se pretende llegar a un acuerdo sobre la moral sin recurrir a nuestras creencias personales". Contra esto, puede decirse, por un lado, que es cierto que en la célebre Posición Original - mecanismo hipotético, pero nunca escena antropológica ni socio-drama representable- las concepciones particulares del bien no son conocidas, pero en modo alguno están excluidas; y, por otro lado, que el liberalismo político explícitamente se sostiene sobre el hecho del pluralismo razonable de doctrinas comprehensivas desde las cuales puede erigirse el consenso traslapado. La clave reside en que Rawls no quiere un modus vivendi, que significaría tolerar hasta que sea posible no tolerar, sino superar la tolerancia por medio del consenso traslapado. Volveremos sobre este punto más abajo.

Así las cosas, para la concepción deontologista, la tolerancia es

un ideal moral (o una propiedad disposicional o una virtud de la justicia) que solo puede justificarse a través de razones morales. Entiéndase que para esta clase de filósofos [liberales y deontologistas] la tolerancia es una virtud de la justicia a la que solo tienen acceso aquellas personas razonables que han desarrollado un sentido de justicia (en el sentido que Rawls le da a los términos de 'razonable' y 'sentido de la justicia') [énfasis propio].

A esta definición, que coloca a la tolerancia como una virtud de las personas $-\mathrm{y}$ lo es, sin duda-, hay que añadirle la perspectiva preferida por el autor de la OLD, quien afirma que su interés está centrado en "el conflicto práctico que enfrenta el sujeto de tolerancia"; más aún, que no le interesa "el conflicto que involucra varios participantes sino el que involucra a un solo participante: el sujeto de tolerancia". El problema de esta perspectiva radica en que pone fuera de foco uno de los rasgos principales del liberalismo político rawlsiano (y de la teoría de la justicia como equidad), esto es: que los principios 
de justicia tienen como objeto primario a la estructura básica y no a las actitudes individuales. Para Rawls, como se sabe, "la justicia es, la primera virtud de las instituciones sociales"3. Así, el "principio de tolerancia" rawlsiano está inscripto en la gramática de las instituciones y no depende, primordialmente, de las actitudes de las personas. Y cuando se trata del problema de la estabilidad — como veremos en el acápite siguiente-, el consenso traslapado no se alcanza entre personas tolerantes, sino entre personas razonables. Una persona tolerante solo apostaría al modus vivendi, y no al consenso profundo entre doctrinas razonables.

Puesto que la OLD está centrada en la perspectiva del sujeto de la tolerancia (un individuo enfrentado a las circunstancias o condiciones de tolerancia), la salida que Rawls tendría en este caso, sería doble. Por un lado, podría insistir en que su teoría tiene como objeto a la estructura básica de la sociedad y que no le conciernen - por razones de justicia - las actitudes personales. Y esto nos remite a la segunda vía de escape abierta a Rawls: su teoría, como bien lo señala González de la Vega, es una concepción politica del liberalismo; y cuando Rawls dice "política" quiere decir que, siendo moral en un sentido amplio, es independiente [freestanding] de las doctrinas comprensivas razonables y de todos sus valores políticos, filosóficos y morales. Por lo tanto, el liberalismo político no sería apto para resolver los problemas que debe enfrentar el sujeto de la tolerancia.

La independencia de la justicia como equidad respecto de las doctrinas comprensivas es, en realidad, el gran cambio que opera ente Teoría de la Justicia y Liberalismo Politico. Rawls admite, en Teoría, que no acierta a establecer la distinción entre filosofía moral y filosofía política y por lo tanto, en esta obra, "una doctrina moral sobre la justicia de alcance general no se distingue de una concepción de la justicia estrictamente política"4; esto es, una concepción que se limite al "dominio de lo políti-

3 Rawls, J., Teoría de la Justicia, México, Fondo de Cultura Económica, 2000 [1971], pág. 17.

4 Rawls, J., Political Liberalism, New York, Columbia University Press, 2006 [2003], pág. xvii. Es nuestra la traducción de todas las citas tomadas de Political Liberalism. 
co". Y el problema nodal que subyace a la revisión que Rawls realiza en su teoría no es el de la tolerancia, sino el de la estabilidad de la sociedad caracterizada por el pluralismo razonable entre doctrinas comprensivas razonables: morales, filosóficas, religiosas, etc 5 .

Por lo tanto, el liberalismo político rawlsiano no pretende ser, tal como denuncia la OLD, un Sistema Normativo Justificante, supremo tribunal ante el cual deben apelarse todos los casos de tolerancia (ya sea entre normas morales o entre nomas éticas y normas morales). Esta denuncia sería atinada si estuviese dirigida a la concepción rawlsiana en Teoría de la Justicia, donde la justicia como equidad constituye una teoría moral comprehensiva. Así, en el acápite sobre la "Tolerancia de los Intolerantes", Rawls explica que las personas en la Posición Original,

comprenden que los principios que reconocen [en especial el principio de igual libertad] han de anular estas creencias [convicciones morales individuales] cuando surja un conflicto; pero, por otro lado, no necesitan revisar sus opiniones ni rechazarlas cuando estos principios no las sostienen. [...] Lo que es esencial es que, cuando las personas con diferentes convicciones hagan exigencias conflictivas a la estructura básica como asunto de origen politico, juzguen estas reclamaciones mediante los principios de justicia. Los principios que fueron elegidos en la posición original son la base de la moral politica. No solo especifican los términos de la cooperación entre las personas, sino que definen un pacto de reconciliación entre las diversas religiones, creencias morales y formas de cultura a las que pertenecen"6.

Como se ve, en su primera gran obra, los principios de justicia parecen cumplir el rol de SNJ, como árbitro último de las diputas entre convicciones éticas, ya que tales principios tienen la capacidad de "anular las creencias" que pertenecen - para usar el lenguaje de la OLD - al Sistema Normativo Básico (SNB). De este modo, la teoría de la justicia en tanto teoría moral es capaz de derogar o confirmar creencias, hecho crucial para justificar (o no) un acto de tolerancia.

5 Ibíd, pág. xviii, passim.

6 Rawls, J., Teoría de... op. cit, pág. 210; énfasis propio. 
Sin embargo, ya aparecen aquí — aunque sin demasiada claridadlos elementos de la futura concepción estrictamente política. Por un lado, se destaca el hecho de que el conflicto que reclama tolerancia, aunque pueda originarse en casos individuales, tiene que resolverse en la instancia de la estructura básica — institucional - como "asunto de origen político". Por otro, los principios de justicia definen los términos de cooperación entre las personas, y definen "un pacto de reconciliación" entre sus creencias, convicciones, valores, etc. Los principios de justicia como especificación de los términos de la cooperación social —aplicados siempre a la estructura básica - serán una constante en la concepción política posterior; el pacto de reconciliación, por su parte, dará origen a una idea menos densa: el consenso traslapado.

En Liberalismo Político, entonces, la visión comprensiva de Teoría cambia dramáticamente: la moral política ya no es comprensiva, sino solo una concepción política de la justicia, independiente respecto de cualquier doctrina comprensiva razonable; y su fin ya no es la reconciliación, sino la convivencia en el marco de un pluralismo razonable, el cual es un hecho, un dato duro de las sociedades democráticas contemporáneas. En rigor, Rawls considera que la meta del liberalismo político es construir una concepción puramente política de la justicia que pueda ser refrendada por esa pluralidad de doctrinas comprensivas que están contenidas en las sociedades democráticas. "La intención - dice Rawls - no es reemplazar esas perspectivas comprensivas, ni darles un basamento verdadero. En realidad, esa intención sería ilusoria, pero este no es el punto. El punto es, en cambio, que hacer tal cosa no sea asunto del liberalismo político"7. No hay lugar a dudas: mientras en Teoría los principios podían anular creencias, ahora no pueden siquiera reemplazarlas.

Más aún: el liberalismo político es una concepción que no pretende estar por encima de las doctrinas comprensivas sino que, como alega Rawls, corresponde al limitado y muy específico dominio de lo político, en el marco de una situación de consenso traslapado en la que cada ciudadano afirma, a la vez, su propia doctrina comprensiva y la concepción

7 Rawls, J., Political... op. cit., pág. xx. 
política de la justicia como equidad, que están "de algún modo relacionadas". Así, "en algunos casos, la concepción política es simplemente la consecuencia de, o la continuación de, la doctrina comprensiva de un ciudadano; en otros casos puede estar relacionada como una aproximación aceptable, dadas las circunstancias del mundo social" 8 . Por eso, resulta crucial la afirmación de que la concepción política es imparcial respecto de otras doctrinas, y esto se manifiesta en que "el liberalismo político no ataca ni critica ninguna visión razonable. Y como parte de esto, no critica, ni mucho menos rechaza, ninguna teoría particular sobre la verdad de los juicios morales"9. Una vez más, al situarse en el dominio de lo político, con la estructura básica como objeto primario, la concepción política de la justicia no deroga ni confirma — ni reemplaza, ni ataca, ni critica, ni rechaza- las convicciones "éticas" de las personas.

La coexistencia de la concepción política de la justicia como equidad y de las doctrinas comprensivas tiene, sin dudas, una cierta afinidad estructural con la división entre el Sistema Moral Básico y el Sistema Normativo Justificante, pero este dualismo, explica Rawls, "no es un dualismo que se origine en la filosofía [sino] que se origina en la especial naturaleza de la cultura política democrática caracterizada por el pluralismo razonable"10. Por ello, el dualismo de marras no es parte de un dispositivo deontológico concebido para resolver los casos de tolerancia; la concepción política de la justicia como equidad no es un SNJ, por dos razones: porque no pretende ser universal (ya que se limita al domino de lo político en sociedades con culturas democráticas y dispositivos constitucionales), y porque no solo no juzga a las doctrinas comprensivas, sino fundamentalmente, porque no pretende "reemplazarlas". Siendo esta la explícita intención de Rawls, es difícil sostener que los principios de justicia política puedan derogar alguna norma que esté cuestionada en un conflicto de tolerancia, o que pueda

8 Ibid., pág. xxi; énfasis propio.

9 Ibid., págs. xxi-xxii; énfasis propio.

${ }^{10} \mathrm{Ibid}$., pág. xxiii. Según Cohen, este dualismo rawlsiano corresponde a la típica división burguesa entre Estado y sociedad civil, entre el cielo político igualitario y el mundo real plagado de desigualdades materiales. Ver: Cohen, G. A., Rescuing Justice and Equality, Cambridge, Harvard University Press, pág. 1 y ss. 
moralizar el sistema de base. Así, al afirmar su concepción puramente política del liberalismo, Rawls puede blindarse contra la OLD.

$\mathrm{Al}$ ser eminentemente político, este liberalismo rawlsiano mantiene y refuerza la posición ya enunciada en Teoría respecto del locus de la justicia: la estructura básica. En efecto, Rawls cree que "la práctica exitosa y pacífica de la tolerancia en sociedades con instituciones liberales" es un producto netamente histórico, asociado al surgimiento del constitucionalismo liberal. Antes de que emergieran estas formas políticas, "la intolerancia era aceptada como una condición del orden y la estabilidad sociales"11. Así las cosas, "el liberalismo político no es el liberalismo comprensivo", y es imparcial puesto que "no aborda específicamente los temas morales sobre los cuales esas doctrinas [comprensivas] se hallan divididas"12. El liberalismo político, admite Rawls, es "por supuesto, una concepción moral", pero es moral de un modo peculiar, ya que "está concebida para un tipo de objeto específico, esto es, las instituciones políticas, sociales y económicas"13, que constituyen la estructura básica. Y la estructura básica no incluye las decisiones particulares, ya que está formada solamente por "las principales instituciones políticas, sociales y económicas [que] se articulan en un sistema unificado de cooperación social de una generación a la siguiente"14.

Esta estructura básica es solo una parte del sistema normativo social; es la parte que constituye el objeto de los principios de justicia. La otra parte está formada por todas las restantes esferas y espacios de la vida social, donde están situados los valores no políticos, que se aplican estrictamente a las personas y a las asociaciones. Así, dice Rawls

[1]o que buscamos, en efecto, es una división institucional del trabajo entre la estructura básica y las reglas que se aplican directamente a los individuos y a las asociaciones, y que han de ser respetadas al realizar transacciones particulares. Si es posible establecer esta división del trabajo, entonces los individuos y

${ }^{11}$ Rawls, J., Political... op. cit. pág. xxvii.

${ }^{12}$ Ibíd., pág. xxx.

${ }^{13} \mathrm{Ibíd}$., pág. 11.

${ }^{14}$ Ibid., pág. 11. 
las asociaciones tendrán libertad para promover sus fines más eficazmente, en el marco de la estructura básica, con la certeza de que en otras partes del sistema social se habrán hecho las necesarias correcciones para conservar la justicia de trasfondo ${ }^{15}$.

Así, Rawls insiste en que los principios de justicia, y en particular el Principio de Diferencia, no se aplican "a transacciones o distribuciones particulares, ni a las decisiones de individuos y asociaciones, sino más bien al trasfondo institucional en el que se llevan a cabo estas transacciones y decisiones"16. Más aún, "el liberalismo político presenta [...] una concepción política de la justicia para las principales instituciones de la vida política y social, no para la totalidad de la vi$d a^{\prime 17}$. En consecuencia, el liberalismo político permanece imparcial - pero no escéptico ni indiferente - frente a los conflictos particulares de tolerancia y solo rige sobre la estructura básica. La meta del liberalismo político es proporcionar un conjunto de principios de justicia para una sociedad democrática caracterizada por el pluralismo de doctrinas comprensivas razonables. El liberalismo político, entonces, según lo concibe Rawls, brinda principios justos y mecanismos para lograr estabilidad a lo largo del tiempo. Esto es crucial: la meta no es la tolerancia, sino la estabilidad del sistema.

\section{II.2. Mucho más que tolerancia: un consenso traslapado}

Vale insistir: el consenso profundo - ya insinuado en Teoría de la Justicia y desarrollado en Liberalismo Político-, y no la tolerancia, es la "promesa normativa" para superar los conflictos entre valores en una sociedad caracterizada por el pluralismo razonable. Es precisamen-

${ }^{15}$ Ibid., págs. 268-269.

${ }^{16} \mathrm{Ibid}$., págs. 264-265. La restricción del alcance de los principios de justicia a la estructura básica es uno de los temas centrales de la crítica de Cohen a Rawls. Ver: Cohen, G. A. op. cit., capitulo 3; y Cohen, G. A., "Where the Action Is: On the Site of Distributive Justice", Philosophy \& Public Affairs, 26, 1, 1997, págs. 3-30.

${ }^{17}$ Rawls, J., Political Liberalism, op. cit., pág. 175. énfasis propio. 
te por este rasgo que Rawls, curiosamente, coincidiría con la OLD cuando esta afirma que "la tolerancia es impracticable cuando se trata de conflictos morales profundos", pero no estaría de acuerdo con la idea de que "la tolerancia se convierte en un mecanismo tiránico de la moral liberal". En el primer caso, como Rawls tiene en mente un consenso traslapado que va más allá de la tolerancia, esta resulta impracticable ya que no resuelve el problema sino de modo transitorio. En el segundo caso, la denuncia contra la tiranía de la tolerancia - como resultado del predominio del SNJ_, no queda justificada si se toma en serio la imparcialidad y la restricción en el alcance de los principios de justicia del liberalismo político.

Es preciso enfatizar que, para Rawls, el conjunto de las convicciones relevantes a ser toleradas incluye tanto las convicciones morales como las no morales (éticas, estéticas, de gustos, etc.). Es decir, la tolerancia se extiende sobre todas las cuestiones sobre las que puedan darse razones. Ahora bien, según la OLD, uno de los resultados de la tolerancia liberal es la moralización del mundo ético por medio de la apelación al Sistema Normativo Justificante. Y esto se origina en el rasgo ya mencionado del deontologismo, según el cual lo correcto tiene estricta prioridad sobre lo bueno; esto es, lo moral sobre lo ético, y lo razonable sobre lo racional. En tal sentido, González de la Vega nos recuerda que "cuando en la 'posición original' de Rawls lo racional es absorbido por lo razonable, aquel se subordina de manera absoluta a este. Esta subordinación significa que los principios de justicia acordados tienen una prioridad lexicográfica frente a cualquier concepción del bien". Es cierto que en las circunstancias altamente formalizadas de la Posición Original, las personas morales no conocen sus respectivas concepciones del bien; y solo en este sentido pude hablarse de una subordinación de lo racional frente a lo razonable. Pero la prioridad lexicográfica no significa otra cosa que eso: prioridad, algo muy distinto a la anulación, derogación o confirmación. La relación de los principios de justicia con los otros valores no políticos $\mathrm{y}$, en general, con las diversas doctrinas comprensivas razonables, no puede ser calificada en términos de absorción o subordinación. Los principios de justicia son aceptados por la vía de la deliberación en la 
Posición Original, donde no se conocen las diversas concepciones del bien, y por la vía de la razón pública, ya que pueden ser objeto de un consenso traslapado, en el cual las concepciones del bien no solo son conocidas sino que hacen su parte en sostener la concepción política de la justicia.

El cambio que experimenta la visión rawlsiana entre Teoría y Liberalismo Político obedece en gran medida a problemas internos de la estructura argumental, en cuanto a cuestiones externas no del todo reconocidas por Rawls. Teoría era un texto de la Guerra Fría, un momento en que las aspiraciones universales cifradas como grandes narrativas aún estaban en pie; Liberalismo Politico es mucho menos ambicioso, si se quiere, ya que intenta preservar un mínimo de liberalismo ante la irrupción de la ultraderecha religiosa del Partido Republicano. Por eso mismo, mientras el foco de Teoría está puesto en elaborar una concepción de la justicia como equidad, basada en dos principios, el foco de Liberalismo está puesto en responder a la pregunta por la estabilidad del sistema, concretamente: "¿cómo es posible que pueda existir una sociedad justa y estable cuyos ciudadanos libres e iguales están profundamente divididos por conflictivas e incluso inconmensurables doctrinas religiosas, filosóficas y morales" ${ }^{18}$. Y la respuesta de Rawls, como se sabe, es el consenso traslapado; esto es, el consenso que se alcanza desde el interior de cada doctrina comprensiva razonable en torno a la concepción política de la justicia como equidad.

El consenso en cuestión va más allá de la tolerancia, y supera incluso la noción misma de compromiso político. Está situado por encima del consenso constitucional al que pueden arribar diversos grupos en una sociedad democrática caracterizada por el pluralismo razonable. Así, entonces, en el esquema que propone Rawls (con la estructura básica como objeto primario y el domino de lo político como ámbito de referencia), el argumento centrado en el sujeto tolerante postulado por la OLD parece un tanto fuera de foco. Es cierto, como dice René González de la Vega, que Rawls aplica la tolerancia a la filosofía misma, pero no es del todo exacto que la tolerancia sea la "promesa normativa" 
de su sistema, ya que esta queda eclipsada por la apuesta mucho mayor que hace Rawls al postular la necesidad del consenso traslapado.

No debe creerse que al cambiar la escala y el foco, se ha perdido una de las condiciones fundamentales de la tolerancia; esto es, el poder "para detener, frenar u obstaculizar el acto" que reclama tolerancia. En realidad, Rawls sabe muy bien que la coerción es la ultima ratio de la política y, por ello, al abordar el problema del consenso traslapado, deja en claro que el poder político siempre es poder coercitivo, y que en el caso de las democracias constitucionales la característica especial de la relación política reside en que "el poder político es en última instancia el poder del público, eso es, el poder de los ciudadanos libres e iguales como cuerpo colectivo"19. Esta noción de poder coercitivo legítimo hace que Rawls trace una muy conocida y obvia distinción entre lo político, como algo diferente a lo asociativo, "que es voluntario en modos que lo político no lo es", y a lo familiar, que es "afectivo" de un modo en que lo político no lo es. Así, lo personal, lo familiar y lo asociativo, por no estar definidos en función del poder de coerción colectivo, son ejemplos de lo no político ${ }^{20}$.

Es por lo anterior que en el marco del pluralismo razonable, alega Rawls, resulta "irrazonable o peor que eso querer usar las sanciones del poder estatal para corregir, o castigar, a los que discrepan con nosotros" 21 . He aquí un punto central de la "tolerancia" implicada en el liberalismo político: "es vital", dice Rawls, "que con perfecta coherencia podamos sostener que sería irrazonable usar el poder político para imponer nuestra propia doctrina comprensiva, la cual debemos, por supuesto, afirmar como razonable o verdadera" 22 . Y esto es posible, enfatiza Rawls, porque los valores estrictamente políticos - que son morales, por supuesto - "son grandes valores y son difícilmente superables: estos valores gobiernan el marco básico de la vida social —el verdadero sustrato de nuestra existencia- y especifican los términos fundamenta-

${ }^{19}$ Ibíd., pág. 136.
${ }^{20}$ Ibid., pág. 137.
${ }^{21}$ Ibíd., pág. 138.
${ }^{22}$ Ibíd., pág. 138. 
les de la cooperación política y social"23. Estos valores no son otros que la igualdad civil y política, la igualdad de oportunidades, la reciprocidad económica y las bases del respeto mutuo entre ciudadanos ${ }^{24}$.

El consenso traslapado, afirmado por personas que han desarrollado un sentido de la justicia al vivir bajo instituciones justas, tiene como foco la concepción de justicia política. Ambos elementos, el sentido de justicia y el consenso traslapado, resuelven el problema de la estabilidad de la sociedad caracterizada por el pluralismo razonable. Pero no hay que pensar que a las personas se les pide que el consenso se logre a expensas de sus creencias, sus convicciones, sus valores éticos, etc. Por supuesto que Rawls supone que estamos en presencia de personas suficientemente motivadas como para "resistir las tendencias a la injusticia" y "dispuestas a hacerse justicia unas a otras a lo largo del tiempo"25. Por eso, la justicia como equidad solo puede ser objeto de un consenso traslapado si logra el apoyo de cada ciudadano, que apela a su propia razón dentro de su propio marco de referencia ${ }^{26}$. Pero, vale insistir, a nadie se le exige que renuncie a sus creencias en obsequio a los principios de justicia. No parece, entonces, que exista en Rawls la mentada tiranía de la tolerancia como mecanismo preferido de la moral liberal.

Dados los elementos anteriores, es necesario distinguir entre un modus vivendi y un consenso traslapado. El modus vivendi, alega Rawls, implica un compromiso, un punto de equilibrio entre doctrinas o grupos rivales; es un equilibro que puede quebrarse tan pronto como uno de los actores advierte que puede sacar ventaja. En el modus vivendi la estabilidad es contingente y depende de que no cambien las circunstancias; y "la unidad social es solo aparente"27. En el consenso traslapado, en cambio - siendo la concepción política en sí misma "una concepción moral", con sus principios de justicia y sus virtudes políticas-, las personas afirman dicha concepción política partiendo desde

${ }^{23}$ Ibid., pág. 139.

${ }^{24}$ Ibíd., pág. 139.

${ }^{25}$ Ibíd., pág. 142.

${ }^{26}$ Ibíd., pág. 143.

${ }^{27}$ Rawls, J., Political Liberalism, op. cit., pág. 147. 
"los fundamentos religiosos, filosóficos y morales" que les proporcionan sus respectivas miradas comprensivas ${ }^{28}$. Y que afirmen la concepción política no hace que este acto, aclara Rawls, sea menos religioso, menos moral o menos filosófico. De este modo, a diferencia del modus vivendi, en el consenso traslapado cada doctrina apoya la concepción política desde su propio lugar, y esto genera estabilidad, ya que la adhesión no depende de un "equilibrio de fuerzas relativo"29. Así, quienes afirman la concepción política por sus propias razones no tienen motivos para retirar su respaldo en caso de que su propia posición se vuelva dominante. De este modo, el consenso traslapado va más allá de la tolerancia que, en definitiva, pertenece al momento del equilibrio inestable del modus vivendi ${ }^{30}$.

Se observa aquí un contraste notable respecto de lo que plantea la OLD. No es la concepción política la que acaba juzgando las doctrinas comprensivas - la ética-, sino que la ética es la que afirma, por razones internas, la concepción política. En el consenso traslapado, entonces, puede verse con claridad la división de tareas entre la estructura básica, por un lado, y los individuos y sus asociaciones, por otro. Dice Rawls:

[s]i la justicia como equidad hiciera posible un consenso traslapado habría completado y extendido el movimiento de pensamiento que comenzó hace tres siglos con la aceptación gradual del principio de tolerancia y que condujo hacia el estado no confesional y a la igual libertad de conciencia. Esta extensión es requerida para un acuerdo sobre una concepción política de la justicia, dadas las

${ }^{28}$ Ibid., pág. 147.

${ }^{29}$ Ibíd., pág. 148.

${ }^{30}$ En el marco de una discusión sobre la solo aparente neutralidad del Estado liberal, Terry Eagleton señala: "[c]orresponde a la integridad del estado liberal aceptar a socialistas y conservadores, pero no puede mirar realmente con indiferencia sus proyectos, si se da cuenta de que pueden acabar con su indiferencia [...] Dado que sus verdaderas estructuras permiten inevitablemente generar intereses hostiles a él, no es tanto neutral como tolerante, y la tolerancia es una virtud que solo los sujetos pueden practicar". Ver: Eagleton, T., Las ilusiones del posmodernismo, Buenos Aires, Paidós, 2004, págs. 120-121. 
circunstancias históricas y sociales de una sociedad democrática. Aplicar los principios de la tolerancia a la filosofia misma es dejar que los ciudadanos por sí mismos resuelvan las cuestiones de religión, filosofia y moral de acuerdo con las visiones que libremente afirman ${ }^{31}$.

En suma: el consenso traslapado, heredero de la tolerancia religiosa aceptada como principio en tiempos de la Reforma, es una extensión y un perfeccionamiento de aquel proceso (que fue un modus vivendi). En el liberalismo político, la tolerancia no es un principio tiránico, ni un dispositivo para sancionar la moralización del momento ético; es un momento previo al consenso traslapado. $\mathrm{Y}$ este consenso no tiene aspiraciones universales, puesto que se aplica inequívocamente a un solo tipo de instituciones: aquellas que surgen de sociedades democráticas. Una vez más: no es tarea de los principios de justicia evaluar la verdad o corrección de las visiones particulares, ni arbitrar en cada conflicto puntual en una operación de limpieza sistémica. Esto es lo que significa aplicar la tolerancia a la filosofía misma.

\section{II.3. Valores políticos y esencias constitucionales}

Por lo expuesto en las secciones precedentes, es dable sostener que los principios de justicia - y en particular el principio de libertades iguales- no actúan como Sistema Normativo Justificante. En efecto, al estar restringidos al dominio de lo político no pueden funcionar como el dispositivo que resuelve todos los dilemas morales y no morales. En todo caso, los principios rawlsianos conforman un dispositivo político que permite la convivencia pero no la resolución del dilema moral por vía de la derogación o la confirmación. El vértigo y la tragedia de las decisiones morales no se pierden en el mundo rawlsiano, toda vez que el objetivo minimalista del liberalismo político consiste en lograr un consenso que permita la cooperación de generación en generación. De todos modos, desde la OLD podría alegarse que, según Rawls, los valores políticos son tan importantes que terminan superando a todos los demás, y que esto está en consonancia con la denuncia según la cual 
en el liberalismo deontológico "las normas morales son inderrotables". Pensadores como Rawls, denuncia la OLD, sostienen que

"[s]i queremos actuar moralmente no puede haber ninguna otra consideración, valor o principio distintos a la moral y que derroten las normas que pertenecen a ese ámbito. Los agentes morales están categóricamente vinculados a las normas morales". Esa noción de "inderrotabilidad" se extiende a los derechos individuales. Así, según Michael Sandel —invocado a favor de la OLD—, las teorías deontológicas afirman "el reclamo según el cual ciertos derechos individuales son tan importantes que ni siquiera el bienestar general puede derrotar".

De esta manera, el deontologismo establece una prioridad epistémica y una prioridad moral sobre los derechos individuales tutelados por los principios de justicia. Respecto de la primera, la OLD alega que los principios de justicia no dependen de una concepción del bien, que es "subjetiva y parcial", sino que la "justificación de la que hacen alarde los deontologistas sobre los principios de justicia" se basa en que son "el producto de una decisión colectiva generada a través de un 'consenso traslapado'". En lo que toca a la prioridad espistémica, la OLD incurre, por lo menos, en una simplificación sobre la que diremos solo lo siguiente: el consenso traslapado es la respuesta de Rawls al problema de la estabilidad y obedece a la pregunta de cómo es posible vivir juntos; el consenso traslapado, entonces, no es la instancia en la que se generan los principios de justicia, ya que estos son elegidos en la Posición Original, que sí es una situación hipotética e imparcial. En cuanto a la prioridad moral, el problema consiste en establecer si las normas morales y los derechos son inderrotables, o si, en caso de que haya que elegir entre normas de igual jerarquía, es inevitable incurrir en "un sacrificio o pérdida moral". La OLD sostiene que posiciones como la de Rawls son remisas a aceptar dilemas y suelen calificarlos, cuando los hay, como "déficits epistémicos", como problemas de "consistencia" que deben resolverse lógicamente.

Veamos si el liberalismo es vulnerable a estas acusaciones y, en particular, consideremos la noción de que los principios morales son inderrotables. Según la OLD, el hecho de que los valores de un SNJ sean inderrotables implica la derrota o supresión del valor que los 
desafía. De este modo, se completa un proceso de limpieza sistémica y se genera una situación en el tiempo que termina por convertir a la tolerancia en una noción suicida. Frente a esto, resulta preciso enfatizar que la característica saliente del liberalismo político es que intenta sostener los principios de justicia — que son morales- desde las bases mismas de las diversas doctrinas comprensivas, integradas por normas éticas, filosóficas e incluso morales. Escogidos en las circunstancias hipotéticas de la Posición Original, los principios de justicia son refrendados - por razones de estabilidad - desde cada doctrina comprensiva, y esto no es tarea de ningún sistema, sino tarea de cada una de las personas, en tanto ciudadanos libres e iguales. Dice Rawls:

el liberalismo político intenta, entonces, presentar una explicación de estos valores [políticos] como pertenecientes a un dominio específico - el político- y por lo tanto como una perspectiva independiente [freestranding]. Le corresponde a los ciudadanos individualmente - como parte de su libertad de conciencia - establecer cómo piensan que estos valores del dominio de lo político se relacionan con otros valores de sus doctrinas comprensivas ${ }^{32}$.

Así, los principios de justicia se aplican a la estructura básica de la sociedad, pero la adhesión a los mismos depende de cada ciudadano, que puede sostener dichos principios desde diversas perspectivas comprensivas. Con todo, la OLD insiste en que

la tolerancia [del estilo rawlsiano] no solo no levanta situaciones dilemáticas, sino que implicaría ser un proceso de limpieza sistémica y no un proceso deliberativo mediante el cual, en determinadas circunstancias, detenemos la fuerza normativa de una convicción que consideramos válida e importante para vivir la vida que consideramos merece la pena de ser vivida. 
Sin embargo, el liberalismo político está muy lejos de pretender anular las situaciones dilemáticas e incluso trágicas. En efecto, Rawls tiene una idea distinta a la que se le endilga desde la OLD. Sostiene Rawls:

[u]na concepción política es en el mejor de los casos un marcoguía para la deliberación y la reflexión que nos ayuda a alcanzar un acuerdo politico sobre por lo menos las esencias constitucionales y las cuestiones básicas de justicia. Si parece que ha aclarado nuestra visión y ha vuelto más coherentes nuestras convicciones meditadas; si ha achicado la brecha entre las convicciones conscientes de aquellos que aceptan las ideas básicas de un régimen constitucional, luego, ha cumplido con su propósito político práctico ${ }^{33}$.

Como se ve, no hay derogación ni confirmación de las reglas o convicciones éticas desde los principios políticos. Aquellas permanecen en la esfera particular o asociativa y pueden en todo caso apelar a los principios de justicia cuando están en juego las esencias constitucionales que aseguran la perduración de la sociedad como esquema de cooperación entre ciudadanos libres e iguales. Luego, si la concepción política de la justicia y los valores políticos suelen derrotar (override) a los demás valores, esto no es porque sean superiores, mejores, o verdaderos: lo hacen porque, por el camino de la deliberación, se entiende que son esenciales para preservar las condiciones de la existencia social. Dice Rawls:

las virtudes de la cooperación política que hacen posible un régimen constitucional son, por lo tanto, grandes virtudes. Digo, por ejemplo, las virtudes de la tolerancia y de ser capaz de encontrarse con los otros a mitad de camino, y la virtud de la razonabilidad y el sentido de equidad [fairness].

(...) [Estas virtudes] constituyen un bien público muy importante, parte del capital político de la sociedad. Luego, los valores que entran en conflicto con la concepción política

${ }^{33}$ Ibíd., pág. 156; énfasis propio. 
de la justicia y las virtudes que le sirven de soporte pueden normalmente ser superados porque entran en conflicto con las propias condiciones que hacen posible la cooperación social justa sobre una base de respeto mutuo ${ }^{34}$.

La preservación de las condiciones de la cooperación social, o de la sociedad misma, es el punto límite en el cual los principios de justicia se tornan inderrotables. Incluso los intolerantes han de ser tolerados hasta el momento mismo en que ponen en riesgo la vida social misma. Y esto es así porque los principios rawlsianos son, conviene insistir, políticos y, en consecuencia, mal pueden arbitrar permanentemente en casos que deben ser resueltos por los propios individuos desde sus visiones comprensivas.

El consenso traslapado es el resultado de un proceso de construcción política que parte desde un modus vivendi o consenso constitucional, el cual asegura, por lo menos, instituciones básicas y procedimientos electorales democráticos. En otras palabras, el camino hacia el consenso traslapado se inicia en un modus vivendi que acepta los principios del liberalismo político, tal como el principio de tolerancia fue aceptado como modus vivendi en el siglo XVI luego de la Refor$\mathrm{ma}^{35}$. Pero este aún no es un consenso "profundo". Con las instituciones generadas en el consenso constitucional, andando el tiempo, se avanza desde el pluralismo simple hacia el pluralismo razonable, dadas las características básicas de la disposición de las personas y los arreglos institucionales justos. Y así, el pluralismo razonable da lugar al consenso traslapado en el cual "hay muchas doctrinas comprensivas razonables que entienden que el más amplio reino de los valores es congruente, o respalda, o no está en conflicto con los valores políticos tal como están especificados por una concepción política de la justicia para un régimen democrático"36. Y estas doctrinas no solo no están en conflicto, sino que cada una puede respaldar o sostener los principios

${ }^{34}$ Ibid., pág. 157; énfasis propio.

${ }^{35}$ Ibid., pág. 159.

${ }^{36}$ Ibíd., pág. 169. 
Tolerancia, modus vivendi y consenso en el liberalismo rawlsiano

de justicia por deducción, por aproximación, o sopesando valores diversos hasta encontrar un punto de equilibrio. Dice Rawls:

no necesitamos considerar los reclamos de la justicia política contra los reclamos de esta o aquella visión comprensiva; $n i$ necesitamos decir que los valores politicos son intrínsecamente más importantes que otros valores y esa es la razón por la cual estos son superados $^{37}$.

Solo son superados porque hacen al núcleo existencial de la propia sociedad democrática ${ }^{38}$.

\section{Conclusiones}

Como decíamos al principio, en estas líneas intentaríamos rescatar a Rawls de la OLD pero solo para terminar coincidiendo con González de la Vega respecto de la necesidad de que la tolerancia y otras virtudes sean no solo institucionales, como quiere Rawls, sino también personales; esto es, que la tolerancia sea en efecto una "propiedad disposicional" de las personas, y no una "virtud pasajera". Coincidimos con Bernard Williams, citado por González de la Vega, cuando sostiene que "[1]a ética comprende cuestiones relacionadas con la amistad, la familia, la sociedad, los intereses y los deseos personales, cuestiones que deberían ocupar un lugar especial en nuestras teorías

${ }^{37}$ Ibíd., pág. 157.

${ }^{38}$ En una notable y eficaz argumentación, Roberto Gargarella sostiene que existen superderechos, que son tales por estar "más cerca del nervio democrático de la Constitución". Entonces, aunque acepta que en escenarios de choque de derechos siempre habrá pérdidas - ya que se trata de "situaciones trágicas"-, el punto clave es que la situación dilemática se resuelve por apelación al "corazón de la Constitución", donde reside, por caso, la libertad de expresión como derecho que debe "ser objeto de una protección especial". Este argumento se parece a la noción rawlsiana de que hay valores políticos muy importantes que deben ser preferidos en el momento límite, esto es, cuando están en juego las esencias constitucionales y los propios fundamentos de la coexistencia en una sociedad democrática. Ver: Gargarella, R., Carta abierta sobre la intolerancia, Buenos Aires, Siglo XXI, pág. 22. 
morales". Y del mismo modo, compartimos con González de la Vega su visión de que "la tolerancia debe ser compaginada con teorías morales centradas en el agente, más que en teorías morales centradas en los actos". Ahora bien, estas visiones no hacen gran mella en el liberalismo político de Rawls porque este expresa acabadamente aquello que alguien ha llamado "el arte liberal de separar". Precisamente porque Rawls separa lo político de lo personal, o el SNJ del SNB, y casi no hay conexión entre ambas esferas salvo para casos en que se ponen en juego las condiciones de existencia de la sociedad, es que resulta difícil hablar de tiranía moral, de legalismo, etcétera. La separación rawlsiana entre los principios de justicia y las disposiciones personales, en cambio, es vulnerable a otro ataque: el que ha lanzado con suma habilidad G.A. Cohen, al sostener - y demostrar - que la justicia rawlsiana solo puede darse plenamente si existen actitudes personales congruentes con los principios de justicia, y no ya por una cuestión de estabilidad, sino de justicia. Desde la tradición socialista $-\mathrm{y}$ un intuicionismo radical que desconfía del constructivismo moral rawlsiano-, Cohen afirma el famoso slogan feminista de que lo personal es político. En consecuencia, si las personas actúan de manera maximizadora, no fraterna, y en procura de estímulos para el desempeño productivo, el igualitarismo prometido por el Principio de Diferencia colapsa inexorablemente. Si los principios de justicia se aplican solo a la estructura básica y no a las disposiciones personales, la justicia puede ser apenas un accidente, pero no una condición constitutiva de la sociedad. El reclamo de Cohen, curiosamente, pide que los principios de justicia sí se apliquen a las decisiones personales, que sean una guía para las conductas individuales. Y aquí comienza una nueva discusión, o la misma.

\section{Bibliografía}

Cohen, G. A., Rescuing Justice and Equality, Cambridge (Mass.), Harvard University Press, 2008.

Cohen, G.A., "Where the Action Is: On the Site of Distributive Justice", Philosophy \& Public Affairs, 26, 1, 1997, pág. 3-30 
Eagleton, T., Las ilusiones del posmodernismo, Buenos Aires, Paidós, 2004.

Gargarella, R., Carta abierta sobre la intolerancia, Buenos Aires, Siglo XXI, 2006.

Rawls, J., Teoría de la Justicia, México, Fondo de Cultura Económica, 2000 [1971].

Rawls, J., Political Liberalism, New York, Columbia University Press, 1996 [1993]. 
